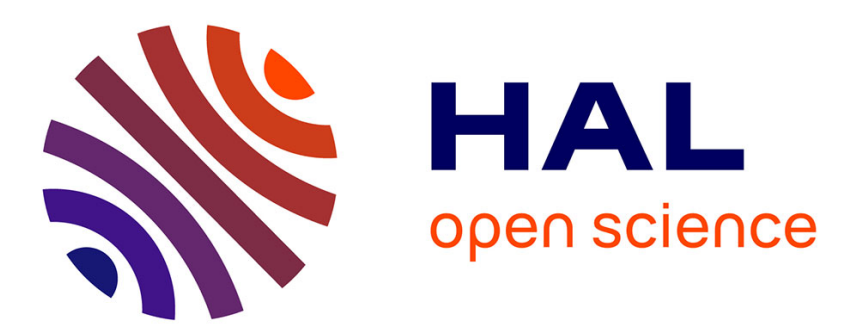

\title{
Kriging Modeling to Predict Viscosity Index of Base Oils
}

Jean-Jerôme da Costa, Fabien Chainet, Benoît Celse, Marion Lacoue-Nègre, Cyril Ruckebusch, Noémie Caillol, Didier Espinat

\section{To cite this version:}

Jean-Jerôme da Costa, Fabien Chainet, Benoît Celse, Marion Lacoue-Nègre, Cyril Ruckebusch, et al.. Kriging Modeling to Predict Viscosity Index of Base Oils. Energy \& Fuels, 2018, 32 (2), pp.2588 2597. 10.1021/acs.energyfuels.7b03266 . hal-01742009

\section{HAL Id: hal-01742009 \\ https://hal.science/hal-01742009}

Submitted on 30 Nov 2018

HAL is a multi-disciplinary open access archive for the deposit and dissemination of scientific research documents, whether they are published or not. The documents may come from teaching and research institutions in France or abroad, or from public or private research centers.
L'archive ouverte pluridisciplinaire HAL, est destinée au dépôt et à la diffusion de documents scientifiques de niveau recherche, publiés ou non, émanant des établissements d'enseignement et de recherche français ou étrangers, des laboratoires publics ou privés. 


\title{
Kriging modelling to predict viscosity index of base oils
}

\author{
J.J. Da Costa ${ }^{\mathrm{a},}{ }^{*}$, F. Chainet ${ }^{\mathrm{a}}$, B. Celse ${ }^{\mathrm{a}}$, M. Lacoue-Nègre ${ }^{\mathrm{a}}$, C. Ruckebusch ${ }^{\mathrm{b}}$, N. Caillol ${ }^{\mathrm{a}}$ and D. Espinat ${ }^{\mathrm{a}}$ \\ ${ }^{a}$ IFP Energies Nouvelles, Etablissement de Lyon - Rond-Point de l'échangeur de Solaize, BP 3, 69360 Solaize - \\ France \\ ${ }^{b}$ Université de Lille, Sciences et Technologies, LASIR CNRS, F-59000 Lille, France \\ E-mail address : jean-jerome.da-costa-soares@ifp.fr
}

\section{ABSTRACT}

Predicting petroleum products properties such as viscosity index (VI) of base oils is an important challenge for refiners as the production always requires more time consuming and costly experiments. Base oils can have very different characteristics depending on which production process they have undergone. In this work, kriging is proposed to predict the VI of base oils obtained from hydrotreatment or / and hydrocracking processes. Kriging is an interpolation method that predicts the value at a given point by computing a weighted average of the observations in the neighborhood of this point. As kriging is closely related to regression analysis, the results obtained were compared with multilinear regression (MLR). Results show that kriging and MLR have very close performances for hydrotreatment data (base oil with viscosity indices ranging from 9 to 113 ) for which $63 \%$ of the validation samples are predicted within the confidence interval of the standard measure. For hydrocracking data (base oils with viscosity indices ranging from 85 to 126 ) kriging provides better results as $62 \%$ of the validation samples are predicted in the confidence interval of the standard measure against $46 \%$ for MLR. In light of these results, we discuss the potential of kriging to deal with both linear and nonlinear situations.

Keywords: Kriging, Multilinear Regression, Hydrotreatment, Hydrocracking, Base oil, Viscosity Index, Total liquid effluent

\section{Introduction}

Despite of high costs of investment due to rough operating conditions, hydrocracking has become an attractive option for the upgrading of vacuum gas oil (VGO). The main reason is the increasing demand for middle distillates (e.g. kerosene and diesel cuts) ${ }^{1,2}$. VGO cut is a petroleum fraction which contains compounds with boiling points above $370^{\circ} \mathrm{C}^{3}$. It is obtained by distillation of atmospheric residue of crude oil ${ }^{4}$. The relatively high amounts of organic nitrogen and sulfur in VGO makes it not valuable as they are undesirable in 
the final products (e.g. diesel, base oil). The purpose of hydrocracking units is to convert VGO into more valuable fractions, conforming to ever more stringent product quality specifications ${ }^{5}$. Many types of hydrocracking process are currently used in the petroleum industry. It consists in two successive steps: hydrotreatment step (HDT) which is performed to remove organic nitrogen and sulfur, by hydrodenitrogenation (HDN) and hydrodesulfurization (HDS) reactions, and hydrocracking step (HCK) where large hydrocarbons compounds are broken up and hydroisomerized simultaneously. Hydrocracking unit provides a total effluent which is submitted to atmospheric distillation. Light and middle distillates (naphtha, kerosene, diesel) are then obtained. The unconverted fraction (UCO) is upgraded to base oil using solvent or catalytic dewaxing ${ }^{6}$. As products quality depends on hydrocracking experimental conditions, process optimization requires time consuming and costly experiments. High Throughput Experimentation (HTE) units are then increasingly used but provide a too small quantity of total liquid effluent (liqtot) to perform distillation step. Furthermore, the standard measurement methods (ASTM and EN methods) of petroleum cuts properties also require relatively long time and a significant quantity of products. For example, viscosity index of base oils acquisition requires at least $106 \mathrm{ml}$ of UCO and 14 hours analysis time. Thus, modeling physicochemical properties of hydrocracking products is a key point. In addition, it allows better understanding of these properties.

VI measures the effect of temperature variation on the oil viscosity ${ }^{7}$. This characteristic is essential to ensure engine maintenance under different weather conditions. The measurement of VI is obtained from a logarithmic scale based on two reference oils: the former is a L series lube oil which contains a high amount of naphtenic compounds and represents a high viscosity temperature dependence; the latter is a $\mathrm{H}$ series lube oil with a high amount of paraffinic compounds which refers to a low viscosity temperature dependence. They are assigned a VI value of 0 and 100 respectively. The VI is then determined by interpolation or extrapolation (if a given oil sample has a VI above 100) of the tabulated $\mathrm{H}$ and L viscosities ${ }^{7}$. VI of base oils is particularly difficult to model since it depends on complex molecular parameters of their constituent compounds. First works ${ }^{8-11}$ aimed at finding a relation between VI and temperature through thermodynamic parameters. VI was correlated to the flow of Gibbs activation energy using Arrhenius-type law ${ }^{12}$, but Verdier et al. ${ }^{13}$ have recently shown that these relations are not always adequate for petroleum cuts because they do not include the molecular effects. The VI dependence on molecular composition was first illustrated through the project led by the American Petroleum Institute ${ }^{14}$. Lynch ${ }^{15}$ suggested to rank hydrocarbon type according to their VI value. He observed that n-paraffinic compounds have higher VI, followed by monobranched isoparaffins, then multiple branched isoparaffins and mononaphtenes and monoaromatics with long alkyl chains, etc. 
Many works were then proposed in the literature to model VI from physicochemical and analytical data of petroleum cuts. Spectroscopic techniques such as ${ }^{13} \mathrm{C}$ nuclear magnetic resonance (NMR) ${ }^{16}$ or near infra-red (NIR) ${ }^{17}$ are increasingly used to characterize petroleum cuts through multivariate analysis. Thus, Kobayashi et al. ${ }^{18}$ correlated the VI of base oils obtained from hydrocracking of Fischer-Tropsch waxes to the ratio $(A C N)^{2} /$ $A B N$ where $A C N$ and $A B N$ denote the average carbon number and the average branching number respectively and were estimated from ${ }^{13} \mathrm{C}$ NMR spectra of base oils. Sharma et al. ${ }^{19,20}$ and Sarpal et. al ${ }^{21}$ used a linear relationship to model VI of base oils from molecular parameters (different types of carbon contents, ${ }^{13} \mathrm{C}$ NMR peaks area corresponding to different branching structures). These works provided important information about the VI dependence on molecular structure of petroleum cuts, but due to the limited number of samples (6 to 8), model robustness can be questioned. Verdier et al. ${ }^{13}$ used a similar approach to model VI of a set of VGOs, base oils obtained from hydrotreated VGOs and base oils produced from hydrocracked VGOs. An average absolute deviation of 3 VI points and a $R^{2}$ of 0.96 were obtained for the 20 oils studied. This study has drawn attention because of the variety of samples analyzed, deriving from both hydrotreatment and hydrocracking processes covering a wide range of VI (-38 to 146).

Multivariate regression models were also used to predict physicochemical properties of petroleum products. Sastry et al. ${ }^{22}$ developed Partial Least of Squares (PLS) models from Attenuated Reflectance Infra-Red (ATRIR) spectra to analyze lube oils covering a wide range of VI (29 to 151). Values of 0.95 and 1.05 were obtained for $R^{2}$ and root mean square error (RMSE), respectively. Artificial Neural Network (ANN) were also applied ${ }^{23}$. Shea et al. ${ }^{24}$ used structural molecular parameter estimated from ${ }^{13} \mathrm{C}$ NMR data to predict VI of base oils. The model provided a very good $R^{2}$ of 0.99 .

Kriging is mainly used and developed in fields of geophysics ${ }^{25,26}$, spatial analysis ${ }^{27,28}$ and computer experiments ${ }^{29}$. To our knowledge, the use of kriging for modeling and predicting physicochemical properties in petroleum field has not been reported in the literature despite the fact that kriging might have many interesting features for this kind of applications. In particular, kriging can deal with both linear and nonlinear data structures.

Analytical data that are currently used to characterize petroleum cuts can be divided into two groups: (i) the basic physicochemical properties (density, refractive index, distillation curves, etc.) ${ }^{3}$ and (ii) the spectral data: Whether the use of spectral data combined with multivariate regression models enables to obtain good results for the prediction of VI, basic properties remain much easier to collect and handle, despite the fact that they provide less chemical information. Furthermore, spectroscopic NMR data are not available in refinery. The 
use of some basic properties to model another one requires to define an adapted correlation to apply classical (non)linear regression methods (which allows direct interpretation of the coefficients). However, the results obtained are strongly affected by the choice of the nature and the number of descriptors used.

This work investigates the potential use of kriging to predict VI of base oils from basic properties of total liquid effluent. The prediction of base oil from properties of an intermediary cut is not common in the literature and constitutes an important challenge of the petroleum industry. The current paper is structured as follows. The first section details databases used in this work (base oils origins and data processing), the second section gives a theoretical approach of kriging method. A third section discusses the choice of descriptors using principal components analysis (PCA) and the quality of the developed models. This paper is focused on the once-through without recycle configuration ${ }^{30}$.

\section{Experimental and methods}

In this paragraph data collection is described first. Details about the measurement of petroleum cuts properties are also given. A description of kriging is then proposed using a basic example. Finally, information about computational tools is given.

\subsection{Hydrocracking process and Data recording}

Oil samples were produced from experimental pilot plants (IFPEN, France, Solaize). An experimental scheme for data recording is given in Figure 1. Vacuum Gas Oil (VGO) is analyzed using standard methods (Table 2) before being hydrotreated using HDT reactor under various operating conditions (LHSV, pressure) and typical catalysts. The resulting total liquid effluents (HDT liqtot) are then collected and also analyzed using standard methods. One part of HDT liqtot is distillated to obtain petroleum products ${ }^{31}$ (Figure 1). The second part is hydrocracked using HCK reactor under various operating conditions (LHSV, temperature, pressure, Organic Nitrogen) and typical suitable different catalysts (Figure 1). The resulting total liquid effluents (HCK liqtot) are also collected and analyzed before being distillated ${ }^{31}$. In both case the distillation step provides unconverted fractions (UCO) corresponding to a boiling range up to a chosen temperature of $370^{\circ} \mathrm{C}$. Finally, base oils are obtained by solvent dewaxing of UCO and their VI are measured using standard NF ISO 2909 method ${ }^{32}$ to complete databases. As mentionned above, VI of base oils acquisition remains constraining for the refiners since its measurement involves to produce at least $106 \mathrm{ml}$ of UCO and 14 hours analysis time around (distillation of liqtot and solvent dewaxing included). 


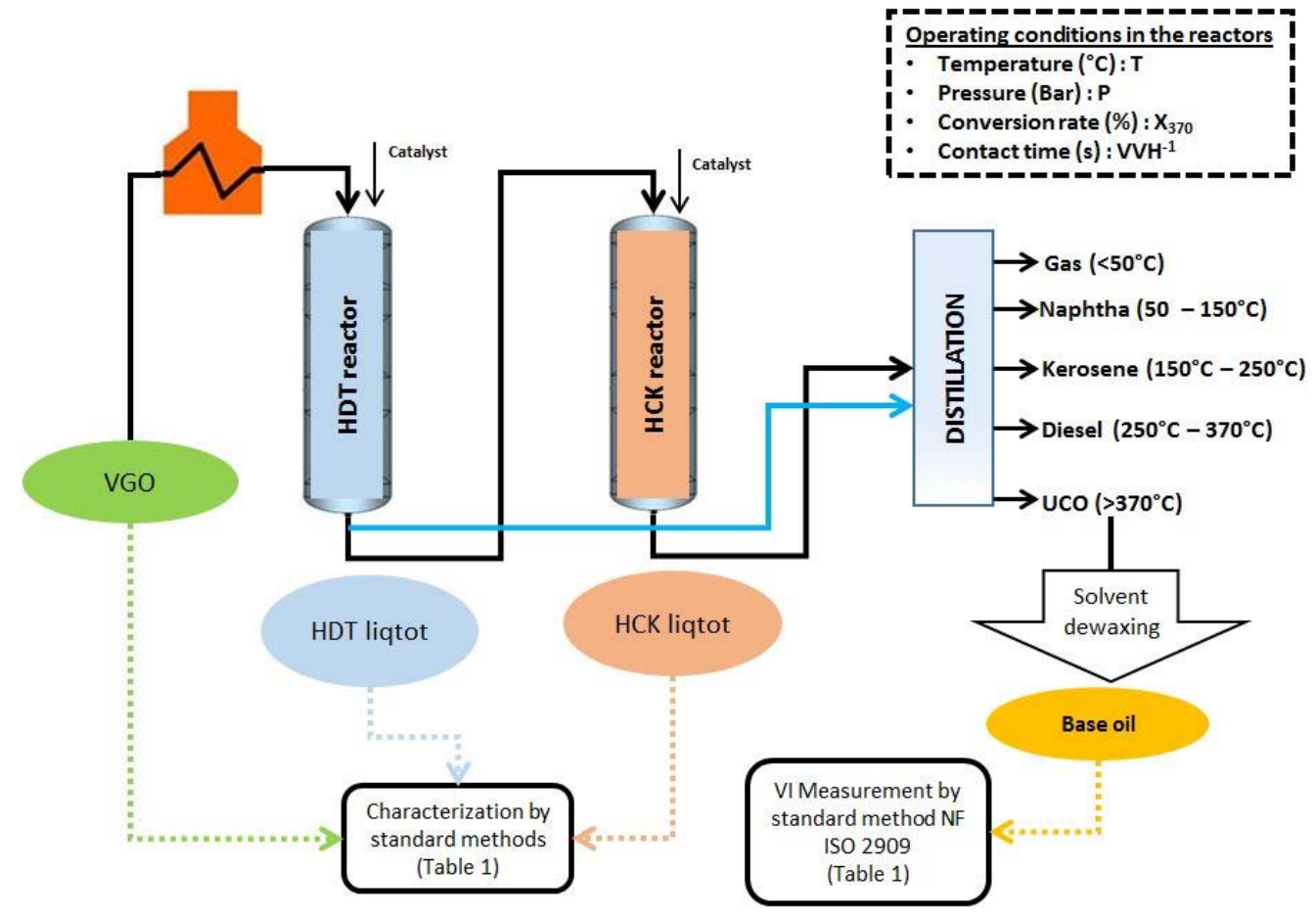

Figure 1. Experimental scheme of HCK process and for data recording

\subsection{Databases}

Two different databases were then built to carry out this work. The first database (HDT) refers to base oils produced from the distillation and solvent dewaxing of HDT liqtot. Vacuum Gas Oil (VGO) from different origins (Arabian Straight Run, Oural Straight Run, Iranian Staight Run, VGO coming from conversion processes (Coker, H-Oil...), were hydrotreated to produce 135 HDT liqtot that provided 135 base oils with VI varying from 9 to 113 .

The second database (HCK) refers to base oils produced from HCK liqtot. In this case, 6 different hydrotreated VGOs were hydrocracked to produce 82 resulting HCK liqtot. Consequently, 82 corresponding base oils samples with VI varying from 85 to 126 were obtained.

A total of twelve different VGO feed were used to produce all these samples. The properties of these VGO are given in Table 1.

Table 1: Properties of the twelve different VGO used to produce samples

\begin{tabular}{|c|c|c|c|c|c|c|c|}
\hline VGO & Origin & $\begin{array}{c}\text { Density at } \\
15^{\circ} \mathrm{C}\left(\mathrm{g} / \mathrm{cm}^{3}\right)\end{array}$ & $\begin{array}{l}\text { Nitrogen } \\
\text { (wt ppm) }\end{array}$ & $\begin{array}{l}\text { Sulphur } \\
\text { (wt\%) }\end{array}$ & $\mathrm{IBF}-\mathrm{FBF}\left({ }^{\circ} \mathrm{C}\right)$ & $\begin{array}{c}\text { Kinematic } \\
\text { viscosity at } 70^{\circ} \mathrm{C}\end{array}$ & $\begin{array}{c}\text { Kinematic } \\
\text { viscosity at } 100^{\circ} \mathrm{C}\end{array}$ \\
\hline A & $\begin{array}{c}\text { Taching } \\
\text { (chinoise) } \\
\text { SR }\end{array}$ & 0,8830 & 1015,00 & 0,1255 & $320,90-622,60$ & 15,97 & 7,51 \\
\hline B & Gansu (Chine) & 0,8974 & 1190,00 & 1,0409 & $348,00-584,00$ & 82,25 & 12,55 \\
\hline $\mathrm{D}$ & Iranian Saniya & 0,9375 & 1300,00 & 2,8743 & $321,90-615,10$ & 124,74 & 11,11 \\
\hline
\end{tabular}




$\begin{array}{cccccccc}\text { E } & \text { Husky } & 0,9580 & 1080,00 & 3,0300 & 215,00-565,00 & 126,70 & 25,20 \\ \text { F } & \text { Arabian Light } & 0,9237 & 835,50 & 2,4100 & 337,00-568,00 & 16,72 & 7,32 \\ \text { H } & \text { Oural SR } & 0,9234 & 1745,00 & 1,7711 & 285,70-605,50 & 72,64 & 7,65 \\ \text { I } & \text { Arabian Heavy } & 0,9439 & 1255,00 & 2,9750 & 346,10-629,40 & 41,37 & 14,48 \\ \text { J } & \text { Sincor } & 0,9849 & 4240,00 & 3,3200 & 286,80-643,00 & 339,20 & 14,00 \\ & \text { HVO+HCGO } & & & & & \\ \text { K } & \text { SR } & 0,9346 & 1755,00 & 2,2375 & 337,70-632,50 & 25,24 & 9,73 \\ \text { L } & \text { Mélange } & 0,9393 & 2315,00 & 2,3300 & 246,00-610,20 & 20,17 & 8,13 \\ & \text { DSV/HCGO } & & & & & & \\ & \text { 75/25 } & & & & & \\ \text { M } & \text { Hoil+Oural } & 0,9314 & 2160,00 & 1,0777 & 292,00-606,20 & 81,87 & 8,06 \\ \text { N } & \text { Etats-Unis } & 0,9208 & 1160,00 & 0,2974 & 158,20-581,40 & 32,07 & 4,69\end{array}$

\section{$2 \quad 2.3$ Measurement of physicochemical properties}

Various physicochemical properties are commonly measured or estimated to characterize petroleum cuts

4 in refinery. The details of standard methods and well-known correlations used in this work are given in Table 2.

5 Note that $T_{i}$ refers to the temperature on simulated distillation following ASTM D2887 method ${ }^{33}$.

$6 C_{370^{+} \text {,reactor input }}$ and $C_{370^{+}, \text {reactor output }}$ are the part of petroleum cuts that corresponds to a boiling range up to

$7 \quad 370^{\circ} \mathrm{C}$ measured before and after the given process respectively. Thus, $X_{370}$ is the conversion of $370^{+}$petroleum

8 cut $^{34}$. In addition, it should be noted that only VI was measured for base oil samples. All other properties used as

9 potential descriptors were measured on feedstock (VGO), hydrotreated liqtot or hydrocracked liqtot.

Table 2: Measured and evaluated properties of feedstock, total liquid effluents and base oil samples

\begin{tabular}{|c|c|c|c|c|}
\hline \multirow[t]{2}{*}{ Property } & \multirow[t]{2}{*}{ Standard Methods } & \multirow[t]{2}{*}{ References } & \multicolumn{2}{|c|}{ Range of value } \\
\hline & & & HDT liqtot & HCK liqtot \\
\hline Viscosity Index (VI) & ASTM D2270 or NF ISO 2909 & $7 / 32$ & & \\
\hline $\begin{array}{l}\text { Density (d) } \\
\text { (in } \text { g.cm }^{-3} \text { ) }\end{array}$ & ASTM D7042 & 35 & $0.85-0.92$ & $0.78-0.87$ \\
\hline Refractive Index (IR) & ASTM D1218 & 36 & $1,44-1,49$ & $1.41-1.46$ \\
\hline Simulated distillation & ASTM D2887 & 33 & & \\
\hline $\begin{array}{c}\left(T_{i}, i=5,10,15, \ldots, 90,95\right) \\
\left(\text { in }{ }^{\circ} \mathrm{C}\right)\end{array}$ & & & & \\
\hline $\begin{array}{c}\text { Carbon type } \\
\text { characterization (Ca, Cp, } \\
\mathrm{Cn} \text { ) (in \%) }\end{array}$ & ASTM D3238 & 37 & & \\
\hline $\begin{array}{l}\text { Number of aromatic rings } \\
\text { (Ra) }\end{array}$ & ASTM D3238 & 37 & & \\
\hline $\begin{array}{l}\text { Molecular Mass (M) } \\
\left.\text { (in g.mol }{ }^{-1}\right)\end{array}$ & IFP 0010350 & Based on ${ }^{3}$ & $266-450$ & $156-366$ \\
\hline $\begin{array}{l}\text { Mean Average Boiling } \\
\text { Point (MeABP) }\end{array}$ & API & 3 & & \\
\hline $\begin{array}{l}\text { Watson characterization } \\
\text { factor }(\mathrm{Kw})\end{array}$ & $K_{w}=\frac{(1.8 \mathrm{MeABP})^{\frac{1}{3}}}{1.001 d}$ & 3 & & \\
\hline $\begin{array}{l}\text { Average Temperature (TM) } \\
\text { (in }{ }^{\circ} \mathrm{C} \text { ) }\end{array}$ & $T M=\frac{T_{10}+T_{50}+T_{90}}{3}$ & 38 & $325-465$ & $203-385$ \\
\hline $\begin{array}{l}\text { Average Weighted } \\
\text { Temperature (TMP) } \\
\text { (in }{ }^{\circ} \mathrm{C} \text { ) }\end{array}$ & $T M P=\frac{T_{5}+2 T_{50}+4 T_{95}}{7}$ & 38 & $393-506$ & $267-441$ \\
\hline Specific gravity (Spgr) & $S p g r=1.001 d$ & 3 & & \\
\hline API Gravity & API.Gravity $=\frac{141.5}{\text { Spgr }}-131.5$ & 3 & & \\
\hline Conversion rate $X_{370}$ (in \%) & $X_{370}=\frac{C_{370^{+}, \text {reactor input }}-C_{370^{+}, \text {reactor output }}}{C_{370^{+}, \text {reactor input }}}$ & 38 & $2-66$ & $20-97$ \\
\hline
\end{tabular}




\section{$1 \quad 2.4$ Theoretical basis}

This paragraph gives a theoretical approach for kriging through a basic example.

\subsubsection{Kriging: a spatial interpolation method}

Several methods have been developed for spatial interpolation in various disciplines ${ }^{39}$. Consider the example illustrated in Figure 2 where a variable $y$ (represented by a color scale) was measured at ten different locations distributed in the two-dimensional space $\left(x_{1}, x_{2}\right)$. The problem consists in estimating $y$ at a new location $\left(s_{0}\right)$ using available observations.

Almost all spatial interpolation methods share the formula in Eq.1 which provides the estimation of $\mathrm{y}$ at the location $s_{0}$ as weighted average of the sampled data,

$$
\widehat{y}\left(s_{0}\right)=\sum_{i=1}^{n=10} p_{i} y\left(s_{i}\right)
$$

where $\hat{y}$ is the estimated value of $y, y\left(s_{i}\right)$ is the measured value at the $i^{\text {th }}$ sampled location $s_{i}$ and $p_{i}$ is the weight assigned to this sampled point.

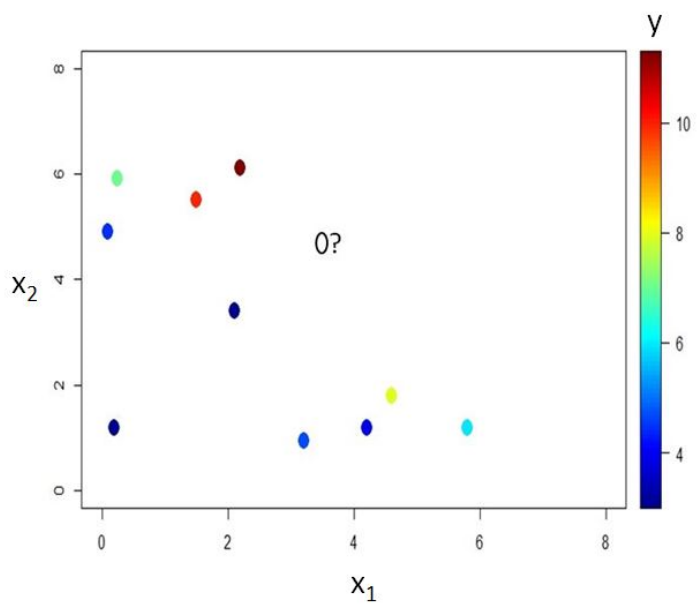

Figure 2. Repartition of sampled data for basic example in a two-dimensional case; colored points $=$ sampled data; $0=$ new point

\subsubsection{Local aspect of kriging}

Spatial interpolation methods can be classified as either global or local methods ${ }^{40}$. Global methods use all the available data of a region of interest to derive the estimation and thus capture general trends. However, these methods require sampled locations to be homogeneously distributed. By contrast, kriging is a local approach. It operates within a small area around the point being estimated and capture local or short-range variation ${ }^{41}$. For kriging, the weights $p_{i}$ depend on (i) the geometrical configuration of the sampled data (spatially close data contain redundant information), (ii) their distance from the new location $s_{0}$ and (iii) the structural characteristics of the variable to estimate (anisotropy, regularity, etc.). In practice, the distribution of weights is 
1

governed by a mathematical model (we refer to section 2.4.3). Figure $3 \mathrm{a}$ and Figure $3 \mathrm{~b}$ respectively represent a Gaussian and a linear distribution of weights for a two-dimensional space and an isotropic variable $y$. The corresponding formulae are also given for each model. In these formulae, $\left(\partial x_{1}, \partial x_{2}\right)$ are the coordinates of any sampled point in the space centered at the new point, $\theta, \theta_{1}$ and $\theta_{2}$ are internal parameters of the illustrated distributions. When a Gaussian structure is used, it defines a local ellipsoidal neighborhood around the unsampled location (Figure 4a). Only the sampled data that have location inside this neighborhood affect the estimated value (i.e. $p_{i} \approx 0$ for $i=1,2,3,4,5,8,9$ ). In addition, the $p_{i}$ exponentially decrease with the square of the Euclidian distance from the unsampled location. When a linear structure is used (Figure 4b), the neighborhood is rectangular and the $p_{i}$ linearly decrease with the distance from unsampled point. In the current example ( $c f$. Figure 4 b), only sampled data 4 and 6 have non-zero weights. Thus, it is more obvious to express the kriging estimator as follows:

$$
\widehat{y}^{K}\left(s_{0}\right)=\sum_{j \in J\left(s_{0}\right)} p_{j} y\left(s_{j}\right)
$$

where $J\left(s_{0}\right)$ is the subset of sampled indexes whose weights are non-zero. Note that kriging is an exact method because it generates a prediction that is the same as the observed value at a sampled point ${ }^{41}$.
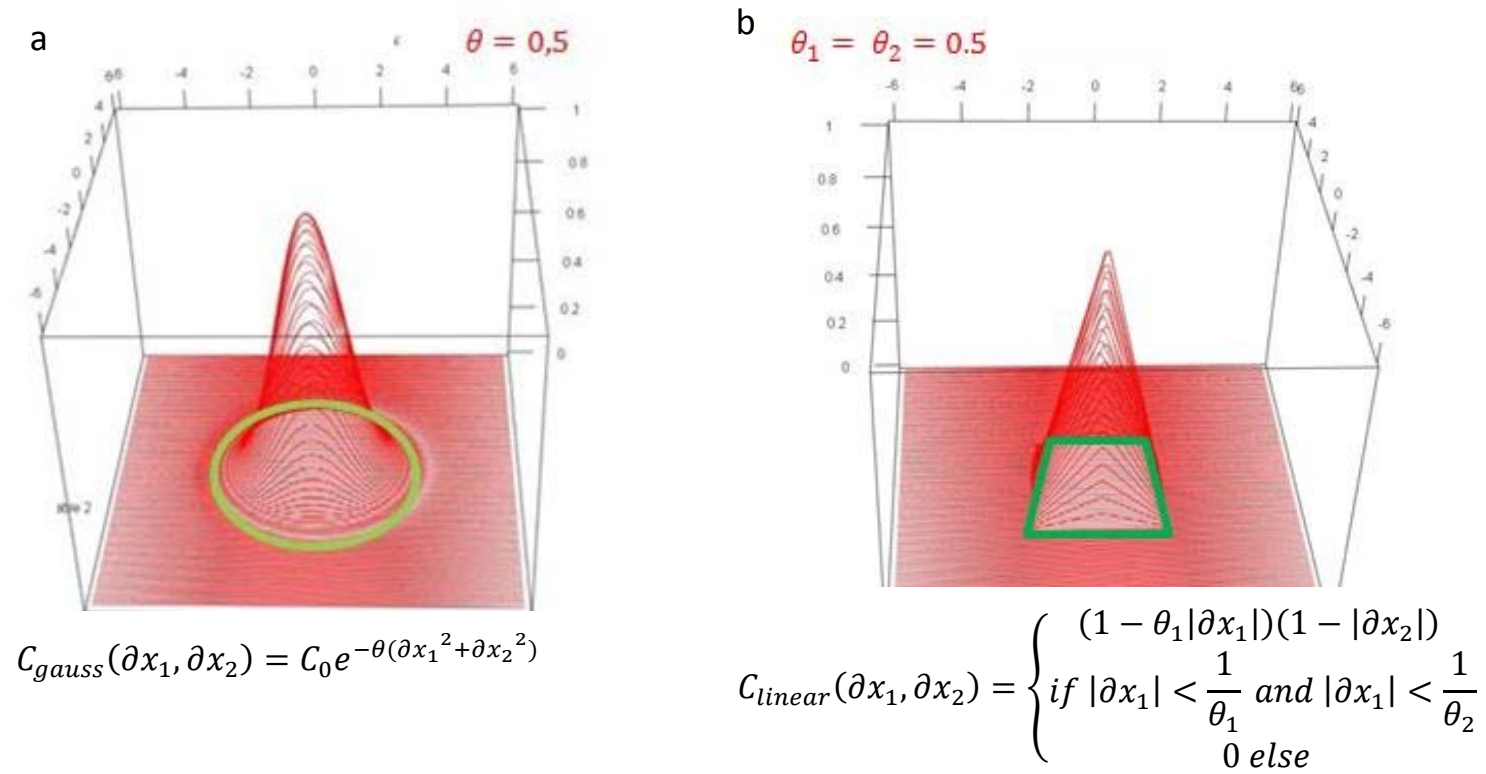

Figure 3. Example of local structures for weights repartition; a) - Gaussian structure ; b) - linear model; green zone delimited area of influence around any unsampled location 
a)

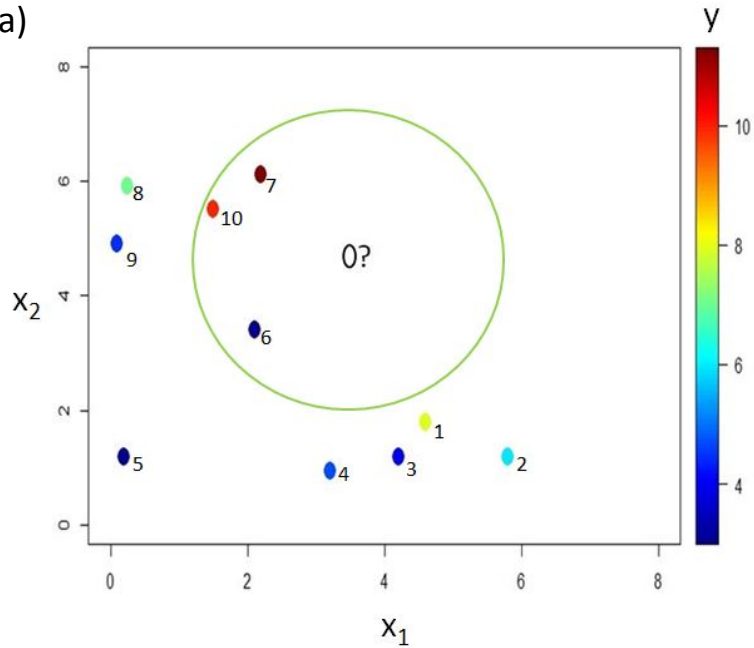

b)

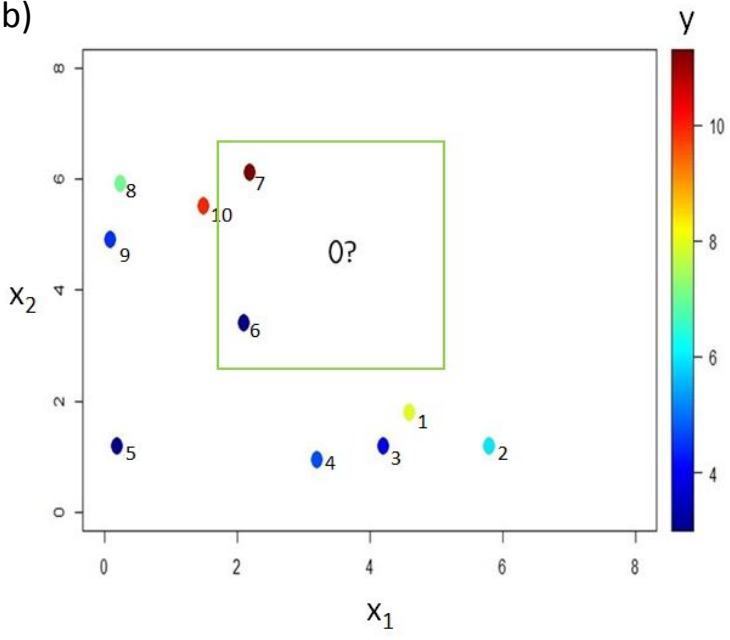

Figure 4. $a$ - Weights distribution when using Gaussian structure ; b - Weights distribution using linear structure

\subsubsection{Statistical approach}

The goal of classical regression is to approximate $y$ with a known mathematical function $f$ (linear, polynomial, etc.). Let $A$ denotes the study area; $y$ can then be expressed as in Eq. 3 at any location $s \in A$ :

$$
y(s)=f(s)+\varepsilon(s)
$$

where $\mathrm{f}$ represents the deterministic part (the global trend) and $\varepsilon(x)$ is the random part (assumed to be normally distributed with zero mean and finite homogeneous variance).

A kriging approach is quite different and can be written as in Eq. 4:

$$
y(s)=\mu(s)+\delta(s)
$$

where $\mu$ is the deterministic part of the expected value of $y$ and $\delta(x)$ is a random variable such as the set $\{\delta(s), s \in \mathrm{A}\}$ describes a multiGaussian process ${ }^{42}$. According to the form of $\mu$ there are three different types of kriging ${ }^{43}$ :

- The simple kriging (SK) where $\mu(s)$ is a known constant $m$;

- The ordinary kriging $(\mathrm{OK})$ where $\mu(s)$ is an unknown constant;

- The universal kriging (UK) where $\mu(s)=\sum_{j=1}^{p} f_{j}(s) \alpha_{j}$ is a linear combination of functions of location $x$.

\subsubsection{The simple kriging predictor}

In case of simple kriging, $\{\delta(s), s \in \mathrm{A}\}$ is assumed to describe a two-order stationary process. This stationarity assumption implies that (i) the expected value of $\delta(s)$ is invariant within the study area and (ii) the covariance between $\delta(s)$ and $\delta(s+h)$ only depends on the separation vector $h$. In what follows $C$ will denote the covariance function related to $\{\delta(s), s \in \mathrm{A}\}$ such that: 
2 Various types of covariance structure are available in the literature ${ }^{27,43,44}$.

3 Let $s_{0}$ denotes a new location and $y_{0}=y\left(s_{0}\right)$ the value to predict. Note $\hat{y}_{0}^{K}$ the simple kriging estimator of $y_{0}$.

$4 \hat{y}_{0}^{K}$ is defined as an optimal linear estimator (i.e. unbiased with minimal variance). The following linear system

5 was obtained by combining this definition to the stationary multiGaussian assumptions:

6

7 Thus, the simple kriging estimator corresponds to the linear estimator of $y_{0}$ which has weights solution of the system. Note that optimal weights directly depends on the covariance structure.

9

$$
\left\{\begin{array}{c}
\sum_{k \in J\left(s_{0}\right)} p_{k} C\left(s_{j}-s_{k}\right)=C\left(s_{j}-s_{0}\right) \\
j \in J\left(s_{0}\right)
\end{array}\right.
$$

This probabilistic approach of kriging is a key point since it allows to consider various approaches in modelling of prediction errors including homogeneous (homoscedasticity) and heterogenous (heteroscdeasticity) situations . Furthermore, although interpolating functions are usually froced to pass through training data, a "nugget effect" referring to an effective variance related to measured values may be introduced in the covariance structure.

\subsection{Assessment of models quality}

Two independent data sets were used for training and validation of the developed models. The training set is used to estimate model parameters in case of regression or to optimize internal parameters of the covariance structure for kriging. The training set for HDT database contains 95 samples whereas the corresponding validation set contains 40 samples. For HCK database, 50 samples were allocated to the training set and 32 samples to the validation set. In all cases, data were divided by performing a space filling algorithm in order to ensure that the most part of predicted points are in situation of interpolation ${ }^{45}$.

Model performances are commonly evaluated by estimating well-known statistics on training and validation sets separately. Since kriging is an exact interpolation method, there is no modelling error at training locations. Thus, a leave-one-out (LOO) error estimation method was used to compare models on training set. The leave-one-out is a special case of cross-validation where the number of folds equals the number of instances in the data set. The learning algorithm is applied once for each instance, using all other instances as training set and using the selected instance as a single-item test set ${ }^{46}$. Each predicted value is then compared with the measured one. The statistics used to evaluate models performances on training and validation test are given in Table 3. 


\begin{tabular}{|c|c|}
\hline Statistics & Formula \\
\hline $\begin{array}{l}\text { Root Mean Square Error of } \\
\text { Cross-Validation } \\
\text { (on training set) }\end{array}$ & $R M S E C V=\frac{1}{n} \sum_{i=1}^{n}\left|y_{i}^{\text {predicted }, \text { LOO }}-y_{i}^{\text {measured }}\right|$ \\
\hline $\begin{array}{l}\text { Root Mean Square Error of } \\
\text { Prediction } \\
\text { (on validation set) }\end{array}$ & $R M S E P=\sqrt{\frac{1}{n} \sum_{i=1}^{n}\left(y_{i}^{\text {predicted }}-y_{i}^{\text {measured }}\right)^{2}}$ \\
\hline $\begin{array}{l}\text { Percentage of point } \\
\text { predicted with a } \\
\text { precision under } \pm \mathrm{IC}\end{array}$ & $\tau_{ \pm I C}=\frac{\sum_{i=1}^{n} 1_{\mid y_{i}^{\text {predicted }}}-y_{i}^{\text {measured }} \mid \leq I C}{n}$ \\
\hline $\begin{array}{l}\text { Percentage of point } \\
\text { predicted with a } \\
\text { precision under } \pm 2 \mathrm{IC}\end{array}$ & $\tau_{ \pm 2 I C}=\frac{\sum_{i=1}^{n} 1_{\mid y_{i}^{\text {predicted }}}-y_{i}^{\text {measured }} \mid \leq 2 I C}{n}$ \\
\hline IC: Confidence Interval & nt method ${ }^{7}$ \\
\hline
\end{tabular}

\subsection{Variable selection}

A variable selection model algorithm was applied to determine suitable final descriptors for modelling VI among all properties presented in Table 2. These properties were chosen by hydrocracking expertise, then they are all relevant. However, they may contain redundant information due to strong correlations. Thus, it may be not relevant to use all of them to develop a linear model. The variable selection algorithm allows to select final descriptors among all available assuming that the model is linear. The best subset of variables is the one that maximizes a predefined criterion. In this work, we used the adjusted correlation coefficient $\left(R_{a d j}^{2}\right)$ which is a penalized release of the classical $R^{2}{ }^{47}$.

\subsection{Used software}

All models have been implemented using statistical software R (version 3.2.2, Copyright (C) 2015 The $R$ Foundation for Statistical Computing). $\mathrm{R}$ is a free software and comes with absolutely no warranty. It is a collaborative project with many contributors. It compiles and runs a wide variety of UNIX platforms, Windows and MacOS. Various performing packages are available and allow to implement models from personal data. The package DiceDesign ${ }^{45}$ was used to perform a space filling algorithm for data selection. The variable selection was performed using R package Leaps. The package "stats" contains function that allow fitting linear regression models and statistical calculations. The package DiceKriging was used to implement kriging model. The function "km" provides different covariance structures and allow to implement all main type of kriging ${ }^{48}$. 


\section{Results and discussions}

\subsection{PCA observation and descriptors research}

A principal component analysis (PCA) ${ }^{49}$ was first carried out to observe HDT and HCK databases and to discuss on potential descriptors (see Table 2) relevance for the prediction of VI. The central idea of the PCA is to reduce the dimensionality of a given data set consisting of a large number of interrelated variables, while retaining as much as possible the variance contained in the data. This is achieved by transforming to a new set of variables called "principal components" (noted PCs), which are uncorrelated (constraints of orthogonality), and which are ordered so that the first few retain most of the variance in all the original data. It should be noted that the variable VI did not contribute to the calculation of principal components.

Figure 5a shows the projection of data whereas Figure $5 \mathrm{~b}$ illustrates the scores of the original variables on the first principal components $\mathrm{PC} 1$ and $\mathrm{PC} 2$ that represent respectively $63.4 \%$ and $31.6 \%$ of the total explained variance for HDT database. The presence of three clusters that refer to different feedstock origins is observed (Figure 5a). A gradient of VI is also clearly observed. This implies that some information related to feedstock origins will be required to well-model the VI and that VI is well explained by PC1 and PC2.

As observed in Figure 5b, PC1 is correlated to the paraffinic carbon content ( $\mathrm{Cp})$, the API.Gravity and $\mathrm{Kw}$ factor (Table 2), and anticorrelated to the variables density (d) and refractive index (IR) and aromatic carbons contents $(\mathrm{Ca})$. Thus, PC1 refers to information about the density of the HDT total liquid effluent analyzed. PC2 is correlated to volatility properties (TM, MeABP, etc.). Furthermore, the closest variable to the VI is the Watson characterization factor $K_{w}$ that can be understood as a ratio volatility/density. Thus, the observations above can be interpreted as follows: in case of hydrotreatment, total liquid effluents that provide base oils with highest VI are those which has high volatility and few density (i.e. low aromatic contents $(\mathrm{Ca})^{3}$ ). By opposition, total liquid effluent with high paraffinic contents provides base oils with highest VI. These observations are in accordance with the correlations proposed by Sarpal et al. ${ }^{50}$ and Sharma et al. ${ }^{19}$. This dependency can be more complex since isoparaffinic and n-paraffinic, compounds that constitute all paraffinic content, can have very different rheological properties according to the branching structure ${ }^{15}$. The aromatic compounds influence that tend to decline the VI of petroleum cuts was also observed by Verdier et al. ${ }^{13}$ and Sastry et al. ${ }^{22}$.

The projection of data and the scores of original variables on PC1 ( $80 \%$ of the total variance explained) and PC2 (11\% of total variance explained) for HCK database are represented in Figure $6 \mathrm{a}$ and Figure $6 \mathrm{~b}$ respectively. The results are quite different that in the previous case. Indeed, no general trend can be observed in Figure $6 \mathrm{a}$ for 
1 the sample distribution regarding to VI. Two data points are relatively far from the others due to their

2 particularly high paraffinic contents. They illustrate the importance to make the distinction between n-paraffinic

3 and isoparaffinic compounds for modelling VI. PC1 is now correlated to density (d), refractive index (IR), naphtenic carbons contents $(\mathrm{Cn})$ and information about volatility (TM, MeABP, etc.) and anticorrelated to Ca,

$5 \mathrm{Cp}$, the VI of feedstock (VI.chg) and the conversion rate $\left(X_{370}\right)$ (Figure 6b). Although VI is not as well explained as in hydrotreatment, it is correlated to PC1 and slightly anticorrelated to PC2. These observations can be 7 interpreted as follows: the simultaneous decrease of aromatics and n-paraffins contents in total liquid effluent, due to the conversion of aromatics into naphtenes and the isomerization of n-paraffins during the hydrocracking process, reduces their effect on density and volatility. Consequently, both properties are now related to the naphtenes and isoparaffins contents. The variable the most correlated to VI is now the VI of feedstock (VI.chg).

That implies that feedstock characteristics significantly affect the VI of base oils. However, the role of paraffinic compounds is more difficult to determine for HCK database since the variable $\mathrm{Cp}$ does not allow to discriminate normal and iso paraffinic carbons. Overall, the presence of paraffinic carbons in total effluent improve the VI of base oil whereas naphtenic carbons $(\mathrm{Cn})$ tend to decrease it. These observations are in total accordance with Sarpal et al. ${ }^{50}$.
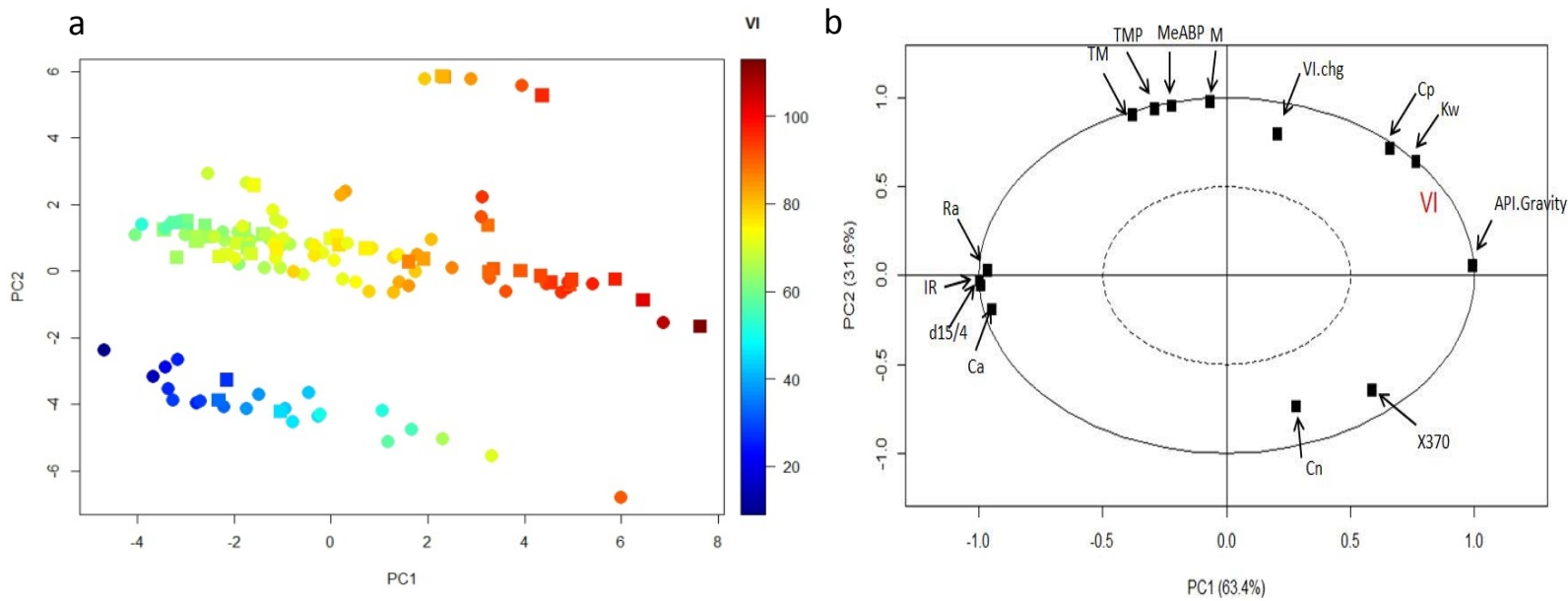

Figure 5. a - Projection of HDT data samples on first factorial plane; circles: training samples; squares: validation samples; color scale: from blue (low VI) to red (high VI); b - Correlation circle of input variables in the first factorial plane (see Table 


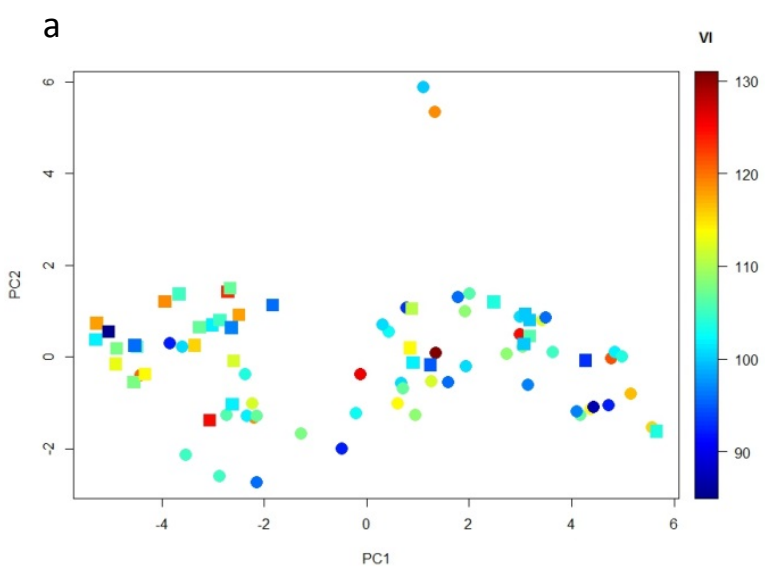

b

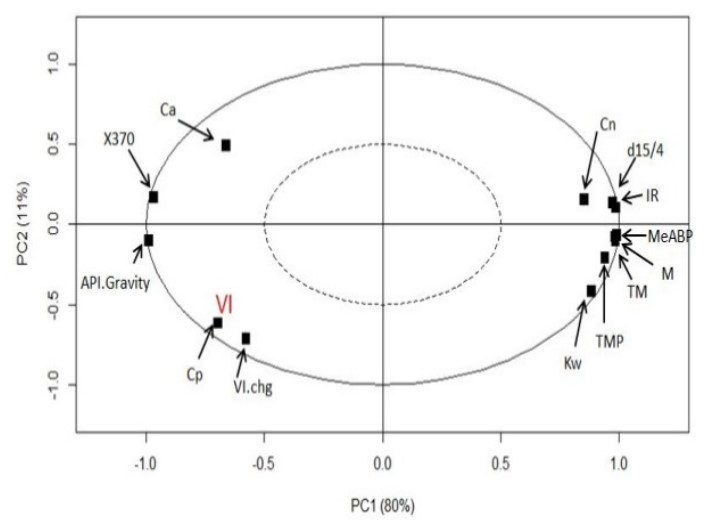

Figure 6. a - Projection of HCK data samples on the first factorial plane; circles: training samples; squares: validation samples; color scale: from blue (low VI) to red (high VI); b - Correlation circle of input variables in the first factorial plane (Table 2)

\subsection{Models comparison}

A variable selection was performed to select final descriptors among all variables used in the PCA analysis. This step is necessary as some of these variables are strongly related, that results in redundant information. Thus, it may be not relevant to use all of them in a regression model. Linear and kriging models were developed using same descriptors in each case. Obtained models were then compared by evaluating performances on training and validation data sets respectively.

For HDT database, parity plots obtained by applying a leave-one-out cross validation to the training set are overlapped for linear and kriging model in Figure 7a: the points predicted using MLR are represented by red stars whereas those predicted with kriging are illustrated by black circles. Both models seem provide very close prediction for the leave-one-out step. This observation is supported by RMSECV values of 2.4 and 1.9 for linear and kriging model respectively (Table 4). Similar observations can be done by considering validation set. Indeed, the parity plots of linear and kriging represented in Figure $7 \mathrm{~b}$ are still very close. RMSEP values of respectively 2.4 and 2.1 (Table 4) for linear and kriging models were obtained. Furthermore, the percentages of points at a precision level under the confidence interval (IC) of the standard method ( \pm 2 points of VI) are equivalent (63.41\%) for both models. All these previous observations show that kriging is slightly better than linear model in case of HDT database. Globally, both models are well-performing since their precision are close to the IC of the measurement method. The fact that linear model provides good performances is consistent with the gradient of VI observed in the previous PCA analysis (Figure 5a).

For HCK database, significant differences can be noted between linear and kriging. Firstly, the parity plots obtained by applying leave-one-out to training data set (Figure 8a) and using model on validation data 
1 (Figure 8b) seem globally less performing for linear model than for kriging one. Furthermore, a RMSECV value

2 of 4.9 was obtained for RLM whereas kriging provided a value of 3.5 (Table 4). Secondly, statistics on

3 validation set are also clearly better for kriging than for MLR. Indeed, a RMSEP value of 2.6 was obtained for

4 kriging against 3.6 for MLR (Table 4). Kriging also provides a better percentage of points at a precision level

5 under the confidence interval (IC) of the standard method (62.5\% against $46.87 \%)$. The observations above show

6 that kriging has clearly better performances than linear model in case of HCK database.

$\begin{array}{cccccc}\text { Data } & \text { Model } & \text { RMSECV } & \text { RMSEP } & \tau_{ \pm \mathrm{IC}}(\%) & \tau_{ \pm 2 \text { IC }}(\%) \\ \begin{array}{c}\text { HDT } \\ \text { Database }\end{array} & \text { Linear } & 2.4 & 2.4 & 63.4 & 92.4 \\ \text { Kriging } & 1.9 & 2.1 & 63.4 & 95.1 \\ \text { HCK } & \text { Linear } & 4.9 & 3.5 & 46.9 & 75 \\ \text { Database } & \text { Kriging } & 3.6 & 2.6 & 62.5 & 90.5\end{array}$

8
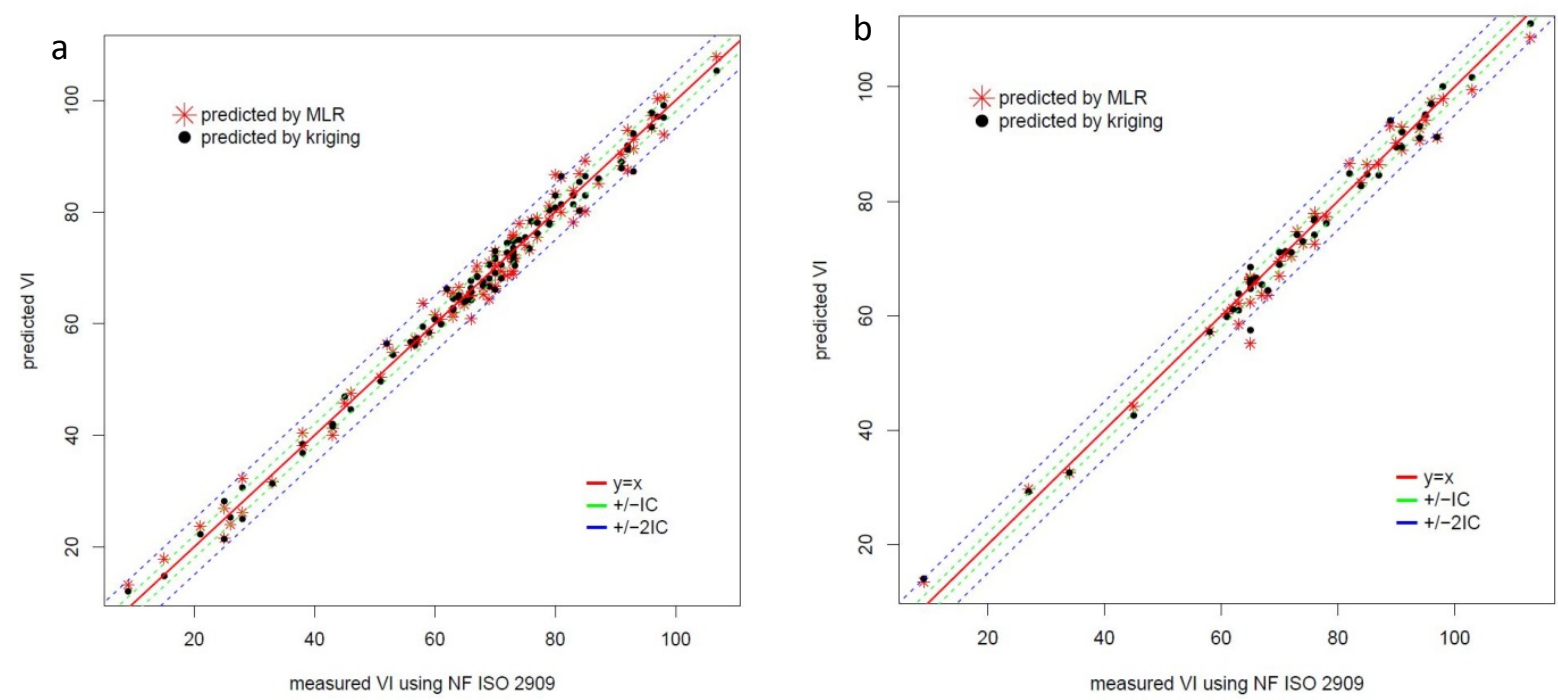

Figure 7. Parity plots for database 1 (HDT); $a$ - On training set (leave-one-out); $b$ - On validation set 

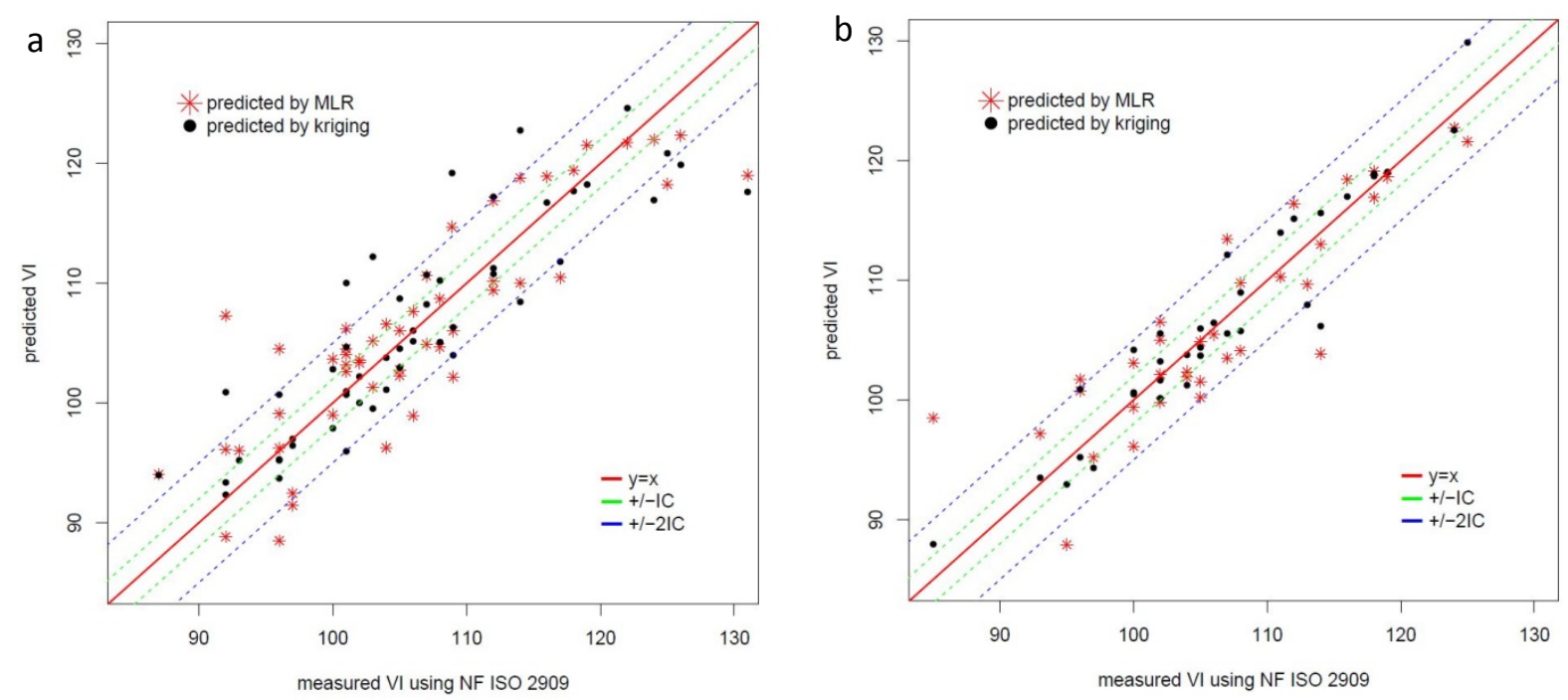

Figure 8. Parity plots for database 2 (HCK); $a$ - On training set (leave-one-out); $b$ - On validation set

3

4

5

6

7

8

9

\section{Conclusion}

Kriging is currently used in geostatistics for modelling field values in localized geographical regions. The dimension is generally less than 3 in this field (spatial coordinates and altitude). The use of kriging in situations where the number of descriptors increases remains problematic as the covariance structure may be too complex to define. This might explain why no example can be found in the literature attempting the modelling of physicochemical data.

In this work, both kriging and linear models were developed to predict VI of base oils produced from hydrotreatment and hydrocracking. In the first case of base oils obtained from hydrotreatment where linear modeling provided good performances in accordance with the reproducibility of the standard measurement method, kriging modeling provided similar performances. For the second case of base oils produced by hydrocracking, MLR performances were insufficient whereas kriging modelling improved performances with identical input variables. The divergence in the MLR model performances according to the considered HDT or HCK database is mainly due to the impact of catalysts which clearly differs according to the referred process. Indeed, catalysts used for hydrotreatment which are generally made of metals such as Molybdenum or Tungsten related to Cobalt or Nickel (NiMo, NiW, etc.) less affect the structure of molecular compounds than those of hydrocracking (presence of zeolite). Globally, the obtained results are particularly important since the descriptors used are not referring to the final product (base oil) but are measured from both feedstock and on the total liquid effluent before the distillation and dewaxing steps. Thus, kriging allows to access to a very important base oil characteristic without performing distillation and solvent dewaxing steps in case of hydrotreatment as well as in 
1 hydrocracking case. To our knowledge, this is the first model for the prediction of VI of base oil using kriging

2 but also for any petroleum products properties and especially from the total effluent global properties. This

3 breakthrough induces an important gain concerning time analysis and sample volume consumption.

4 Another advantage for kriging model is that it provides a measure of prediction uncertainties as it uses

5 stochastic approach ${ }^{51}$. Kriging weights estimation are obtained by solving a linear system ${ }^{25}$, This method would

6 be faced with similar problem in the case of linear model when the number of descriptors will be more

7 significant (as for instance considering spectral data). It should be interesting to adapt this approach to high

8 multivariate situations $(n \gg p)$.

9 


\section{References}

(1) Motaghi, M.; Ulrich, B.; Subramanian, A. Slurry-phase hydrocracking-possible solution to refining margins. Hydrocarbon Processing 2011, 90, 37.

(2) Butler, G.; Spencer, R.; Cook, B.; Ring, Z.; Schleiffer, A.; Rupp, M. Maximize liquid yield from extra heavy oil Next-generation hydrocracking processes increase conversion of residues. Hydrocarbon Processing 2009, 88, 51-55.

(3) Riazi, M. R. Characterization and properties of petroleum fractions, 1st ed.; ASTM International: West Conshohocken, PA, 2005.

(4) Wauquier, J. P. Le raffinage du pétrole: Pétrole brut, produits pétroliers, schémas de fabrication; Publications de l'Institut français du pétrole; Editions Technip, 1994.

(5) Rana, M. S.; Samano, V.; Ancheyta, J.; Diaz, J. A. I. A review of recent advances on process technologies for upgrading of heavy oils and residua. Fuel 2007, 86, 1216-1231.

(6) Daage, M. Zeolites for cleaner technologies. Catalytic Science Series 2002, 3, 167-187.

(7) ASTM D2270. Standard Practice for Calculating Viscosity Index from Kinematic Viscosity at 40 and $100^{\circ} \mathrm{C}, 1991,226 / 91$ (95).

(8) Guo, D. H.; Jiang, L. Rheological behaviour of a new kind of fuel - residual oil, coal and water triplex synfuel. Fuel 1998, 77, 1697-1700.

(9) Evdokimov, I. N.; Eliseev, N. Y.; Eliseev, D. Y. Thermophysical properties and phase-behaviour of asphaltene-containing petroleum fluids. Fluid Phase Equilibria 2003, 212, 269-278.

(10) Martinez-Boza, F.; Partal, P.; Conde, B.; Gallegos, C. Steady-state flow behaviour of synthetic binders. Fuel 2001, 80, 357-365.

(11) Reddy, S. R. A thermodynamic model for predicting n-paraffin crystallization in diesel fuels. Fuel 1986, 65, 1647-1652.

(12) Andrade, E. N. Da C. The structure of the atom; G. Bell: London, 1934.

(13) Verdier, S.; Coutinho, A. P.; Silva, M. S.; Alkilde, O. F.; Hansen, J. a. A critical approach to viscosity index. Fuel, 2009, 2199-2206.

(14) A.P.I. Research Project 42; Pennsylvania State College: State College, Pa., 1941.

(15) Lynch, T. R. Process Chemestry of Lubricant Base Stocks; Boca Raton, 2008.

(16) Adhvaryu, A.; Perez, J. M.; Duda, L. J. Quantitative NMR Spectroscopy for the Prediction of Base Oil Properties. Tribology Transactions 2000, 43, 245-250.

(17) Baptista, P.; Felizardo, P.; Menezes, J. C.; Neiva Correia, M. Joana. Multivariate near infrared spectroscopy models for predicting the iodine value, CFPP, kinematic viscosity at $40{ }^{\circ} \mathrm{C}$ and density at $15^{\circ} \mathrm{C}$ of biodiesel. Talanta 2008, 77, 144-151.

(18) Kobayashi, M.; Saitoh, M.; Ishida, K.; Yachi, H. Viscosity properties and molecular structure of lube base oil prepared from Fischer-Tropsch waxes. Journal of the Japan Petroleum Institute 2005, 48, 365-372.

(19) Sharma, B. K.; Adhvaryu, A.; Perez, J. M.; Erhan, S. Z. Effects of hydroprocessing on structure and properties of base oils using NMR. Fuel Processing Technology 2008, 89, 984-991.

(20) Sharma, B. K.; Adhvaryu, A.; Sahoo, S. K.; Stipanovic, A. J.; Erhan, S. Z. Influence of Chemical Structures on Low-Temperature Rheology , Oxidative Stability , and Physical Properties of Group II and III Base Oils 2004, 952-959.

(21) Sarpal, A. S.; Sastry, M. I.; Bansal, V.; Singh, I.; Mazumdar, S. K.; Basu, B. Correlation of structure and properties of groups I to III base oils. Lubr. Sci. 2012, 199-215. 
(22) Sastry, M. I.; Chopra, A.; Sarpal, A. S.; Jain, S. K.; Srivastava, S. P.; Bhatnagar, A. K. Determination of Physicochemical Properties and Carbon-Type Analysis of Base Oils Using Mid-IR Spectroscopy and Partial Least-Squares Regression Analysis. Energy Fuels 1998, 12, 304-311.

(23) Wu, C.; Zhang, J.; Li, W.; Wang, Y.; Cao, H. Artificial neural network model to predict cold filter plugging point of blended diesel fuels. Fuel Processing Technology 2006, 87, 585-590.

(24) Shea, T. M.; Gunsel, S. Modeling Base Oil Properties using NMR Spectroscopy and Neural Networks Properties using NMR Spectroscopy and. Tribology Transactions 2008, 37-41.

(25) Dubrule, O. Comparing splines and kriging. Computers and Geosciences 1984, 10, 327-338.

(26) Matheron, G. Traité de géostatistique appliquée; Mémoires du Bureau de Recherches Geologiques et Minières 24; Editions Technip: Paris, 1963.

(27) Cressie, N. A. C. Statistics for spatial data, Rev. ed.; Wiley: New York, Chichester, 1993.

(28) Cressie, N. A. C. The origins of kriging. Mathematical geology 1990, 22, 239-252.

(29) Kleijnen, J. P. C. Kriging metamodeling in simulation: A review; Systemvorraussetzung: Acrobat Reader 2007,13; Center for Economic Research: Tilburg.

(30) Ward, J. W. Hydrocracking processes and catalysts. Fuel Processing Technology 1993, 35, 55-85.

(31) ASTM D86-12. Standard Test Method for Distillation of Petroleum Products at Atmospheric Pressure.

(32) NF ISO 2909. Produits pétroliers - Calcul de l'indice de viscosité à partir de la viscosité cinématique, 2000, 75.080.

(33) ASTM D2887-16A. Test Method for Boiling Range Distribution of Petroleum Fractions by Gas Chromatography; ASTM International: West Conshohocken, PA, 2016, 16A.

(34) Becker, P. J.; Celse, B.; Guillaume, D.; Dulot, H.; Costa, V. Hydrotreatment modeling for a variety of VGO feedstocks: A continuous lumping approach. Fuel 2015, 139, 133-143.

(35) ASTM D7042-14. Standard Test Method for Dynamic Viscosity and Density of Liquids by Stabinger Viscometer (and the Calculation of Kinematic Viscosity ), 2014, 14.

(36) ASTM 1218-16. Test Method for Refractive Index and Refractive Dispersion of Hydrocarbon Liquids; ASTM International: West Conshohocken, PA, 2016, 16.

(37) ASTM D3238-95. Standard Test Method for Calculation of Carbon Distribution and Structural Group Analysis of Petroleum Oils by the $n-d-M$ Method.

(38) Becker, P. J.; Celse, B.; Guillaume, D.; Costa, V.; Bertier, L.; Guillon, E.; Pirngruber, G. A continuous lumping model for hydrocracking on a zeolite catalysts: Model development and parameter identification. Fuel 2016, 164, 73-82.

(39) jin, I.; Heap, A. D. Spatial Interpolation Methods: A Review for Environmental Scientists, Geoscience Australia Record; Appliying Geoscience to Australian most important Challenges 23; Geoscience Australia Record: Geoscience Australia, GPO Box 378, Canberra, ACT 2601, Australia, 2008.

(40) Arnaud, M.; Emery, X. Estimation et interpolation spatiale: Méthodes déterministes et méthodes géostatiques; Hermes Science: Paris, 2000.

(41) Burrough, P. A.; McDonnell, R. Principles of geographical information systems; Spatial information systems; Oxford University Press: Oxford, New York, 1998.

(42) Stein, M. Gaussian approximations to conditional distributions for multi-Gaussian processes. Mathematical geology 1987, 19, 387-405.

(43) Goovaerts, P. Geostatics for natural Resources evaluation. Mathematical geology 1997.

(44) Isaaks, E. H.; Srivastava, R. M. Applied geostatistics, Print book; Oxford University Press: New York, 1989. 
(45) DiceDesign and DiceEval: Two R Packages for Design and Analysis of Computer Experiments, 65

$2(11)$.

3 (46) Encyclopedia of Lubricants and Lubrication; Mang, T., Ed.; Springer Berlin Heidelberg: Berlin, 4 Heidelberg, 2014.

5 (47) Azaïs, J.-M.; Bardet, J.-M. Le modèle linéaire par l'exemple: Régression, analyse de la variance et 6 plans d'expérience illustrés avec $R$ et SAS, 2e éd; Sciences sup : licence 3, master, écoles d'ingénieur; 7 Dunod: Paris, DL 2012.

8 (48) Olivier Roustant, David Ginsbourger, Yves Deville. Package DicKriging: Kriging Methods for 9 Computer Experiments. http://dice.emse.fr/.

10 (49) Jolliffe, I. T. Principal component analysis, 2nd ed.; Springer series in statistics; Springer: Berlin, 11 London, 2002.

12 (50) Sarpal, A. S.; Kapur, G. S.; Mukherjee, S.; Jain, S. K. Characterization by 13 C n.m.r. spectroscopy 13 of base oils produced by different processes. Fuel 1997, 76, 931-937.

14 (51) Wang, D. Kriging regression in digital image correlation for error reduction and uncertainty 15 quantification, University of Liverpool, degree granting institution. 